\title{
الفروض العلمية ماهيتها وأنواعها وطرق تحقيقها
}

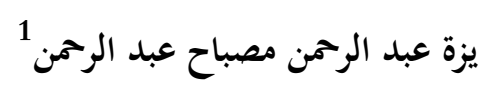

كلية الآداب ـ جامعة مصراتة

تاريخ التقديم: 15-08-2021، تاريخ القبول: 01-12- 2021، نشر إلكترونيا في 05-12-2021

https://doi.org/10.36602/faj/2021.n.18.13

\section{ملخص البحث}

من المسلم به أن المنهج العلمي التجريبي يمر بثلاث مراحل: الأولى مرحلة البحث، والثانية مرحلة الكشف، والثالثة مرحلة البرهان، فإذا كان المكون الأساسي لمرحلة البحث يتمثل في الملاحظة والتجربة، فإن الفروض العلمية هي المكون الأساسي لمرحلة الكشف، إذ تشكل الفروض العلمية عنصراً مكملاً لعنصري الملاحظة والتجربة؛ ذلك لأننا عندما نقوم بالملاحظات ونجري التجارب هدف للوصول إلى المبدأ العام أو القانون، أما التحقق من صحة هذا الفرض أو ذاك فيتم في مرحلة البرهان، وبعد التحقق من صحة الفرض بتريبيًا فإنه يصبح قانونًا كليًا، ومن هذا المنطلق يعد الفرض العلمي عنصرًا جوهريًا في المنهج التجريبي إذ يمثل نقطة البدء في كل استدلال تجريبي، ولولاه لما أمكن القيام بأي بحث، أو تحصيل أي معرفة، وبناءً عليه فإن هذه الدراسة تمدف إلى تسليط الضوء على الفرض العلمي وتوضيح ماهيته، وبيان وظيفته في العلوم التجريبية، فضلاً عن بيان أنواع الفروض وتحديد شروطها، وكيفية التحقق منها.

الكلمات المفتاحية: الفرض العلمي، العلية، الماهية، التجربة، الكشف العلمي، الملدس 


\title{
Scientific Hypothesis: Essence, Types, and Methods of Verification
}

\section{Yeza Abdulrhman Mesbah Abdulrhman}

Faculty of Arts, Misurata University

\begin{abstract}
It is well-known that the experimental method has three steps: the research step, discovery stage, and the proof step. Since observation and experiment are the main components of the research step, scientific hypotheses are considered as a complement to these components. The reason for that is when we make observations and conduct experiments, we aim to reach the general principle or the law. As the verification of the validity of this hypothesis or that, it takes place in the proof step. After verification of the validity of the empirical hypothesis, it becomes a general law, and from this point of view, the scientific hypothesis is an essential element in the experimental method, as it represents the starting point in every experimental inference, and without it, it would not be possible to do any research, or acquire any knowledge. Therefore, the purpose of this study is to shed light on the scientific hypothesis and clarifies its form and its function in the experimental science, as well as stating the types of hypotheses and determining their conditions, and how to verify them.
\end{abstract}

Key words: Scientific Hypothesis, Cause, Essence, Experiment, Scientific discovery, Intention.

1

من المسلم به أن الأزمنة القديمة كانت تعتمد على الأساطير والخرافات في تحديد

الإجابة عن الأسئلة التي تدور حول الهوية والسبية في العالم التجريبي، ولكن مع مرور

الوقت استبدلت هذه الأساطير وتلك الخرافات بالفرضيات والنظريات المتطورة، الأمر 
الذي ينطبق على شتى فروع العلم التجريب، مرورًا بالعلوم الطبيعة، وعلم النفس، وعلم الاجتماع، ووصولا إلى علم التاريخ. وبناء على ذلك فإن الدراسات والأبحاث التي تتناول المنهج الذي يقوم على دراسة مختلف ظواهر الطبيعة، قد تعددت من جانب المناطقة وفلاسفة العلم على حد سواء، وأجمع الجميع على أن المنهج الاستقرائي الذي ينتقل من المعلوم إلى المجهول، يتخذ من الفرض مرحلة أساسية من مراحله، حيث نجد أن العلماء

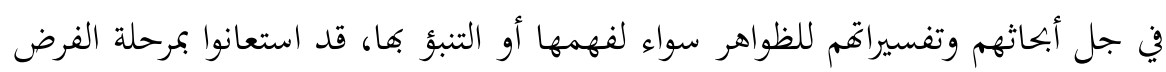
لتحقيق الهدف المنشود.

ومن هذا المنطلق يعتبر الفرض العلمي من أهم خطوات التفكير العلمي؛ فهو الرابط الذي يربط بين كل من الملاحظة والتجربة من جهة، وبين القوانين العلمية من جهة أخرى، فكل قانون علمي ما هو إلا افتراض أكدت التجربة العلمية صدقه، وبالمثل فإن كل ملاحظة أولية ليست ذات قيمة، مالم تنته إلى فروض علمية يمكن التحقق منها بواسطة التجربة. وانطلاقا من أن البحث العلمي يبدأ من مشكلة يصاغ لها عدة فروض لتفسيرها، لذلك يعد الفرض مطلبًا علميًا ضروريًا في توجيه مسار البحث العلمي، فإن ما يهمنا ونخن بهذا الصدد هو توضيح ماهية الفرض العلمي، وبيان وظيفته، وشروطه، وتحديد معايير وسُبل تحقيقه، حتى نصل إلى القوانين والنظريات العلمية.

1.1 تتمحور مشكلة الدراسة في الإجابة عن التساؤلات الآتية: ـ لقد أثار الفرض العلمي العديد من الإشكاليات من بينها إشكالية الاختبار: هل اختبار الفروض يتم بشكل انتقائي؟ وإذا كان الحال كذلك إلى أي حد من الحالات يكون الفرض 
صحيحًا؟ هل في إمكاننا الاعتماد على التحقق في مسألة صدق الفروض العلمية، والحال ذلك هل يوجد ضمان لدقة النتائج التجريبية التي سوف يرفض الفرض على أساسها؟ ـ هل يعد الفرض العلمي قضية كلية أم أنه قضية جزئيج؟ وملاذا لا يكون قضية احتمالية؟ ـ هل يعد الفرض العلمي نتيجة لاستقراء الوقائع الملاحظة، أم أنه نتيجة للاستدلال العقلي، أم أنه عملية منطقية لها قدرة الاستشفاف من الموقفين على وضع فرض يفسر ظاهرة محددة، ويؤلف بين مجموعة من القوانين، ويكون قانونا بعد الاختبار؟ 2.1 - 2.1 أهداف الدراسة: تهدف هذه الدراسة إلى تسليط الضوء على الفرض العلمي وتوضيح ماهيته، وبيان وظيفته في العلوم التجريبية، وتحديد شروطه ومعايير وسُبل اختباره. 3.1 تكمن أهمية هذه الدراسة في الآتي: 1- بيان الأثر الذي تلعبه الفروض العلمية في صياغة القوانين والنظريات العلمية. 2- توضيح أن الاستعانة بالخيال دليل على جرأة الباحث وإقدامه. 3- بيان الوظيفة المزدوجة التي يقوم بها الفرض العلمي في مجال العلوم التجريبية، فهو من جهة يكشف عن القوانين الثابتة، ومن جهة ثانية يبين الصلة التي تربط بين القوانين والتحقق من صحتها. - 2.1 - 2.1 الدراسات السابقة: البحث في الفروض العلمية ليس جديداً فقد حظي بدراسات عديدة لكن في مجالات علمية مختلفة، وكل بجال تناولها بالطريقة التي تتفق وطبيعة بحثه، وبالنسبة لتخصص الفلسفة تعد الدراسات في هذا الموضوع نادرة، وقد عرضه فايز يوسف محمد سكران 
(1993) في رسالته للدكتوراه المعنونة (الفروض العلمية مع مناقشة موقف المعارضين لها من المعاصرين) بجامعة الإسكندرية كلية الآداب قسم الفلسفة. حيث تطرق فيها لتعريف الفرض العلمي وأنواع الفروض العلمية. وإضافة إلى ما تم تقديمه سيتناول هذا البحث باستفاضة الفروض العلمية وذلك من خلال تعريف الفرض لغةً واصطلاحاً، وتتبع ماهيتها عبر العصور المختلفة وبيان وظيفتها وأنواعها وشروطها وعلاقتها بالخيال والحدس إلى جانب ركب معايير اختبارها وبيان الفرق فيما بين المنهج الاستقرائي والمنهج الفرضي.

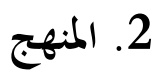

لقد رُوعي في هذه الدراسة عرض الموضوعات وتقديمها بطريقة منطقية تبرز أهم المواضيع، واضعة في الاعتبار الخطوات الواجب اتباعها عند كتابة البحث العلمي، متتبعة في ذلك التسلسل المنطقي، مستخدمة المنهج التحليلي في العرض. تكونت هذه الدراسة من مقدمة ومطالب وخلاصة، حيث احتوت المقدمة على لئل المرصني سبب اختيار الموضوع وأهميته والمنهج المتبع في دراسته، وأما المطالب فخمسة، المطلب الأول ـ الفرض العلمي: الماهية والوظيفة، المطلب الثاني ـ أنواع الفروض العلمية، المطلب الثالث ـ دور الخيال والحدس في الفروض العلمية، والمطلب الرابع ـ شروط الفروض العلمية، المطلب الخامس - سُبل اختبار الفروض العلمية، وأما الخلاصة فقد تضمنت أهم نتائج الدراسة.

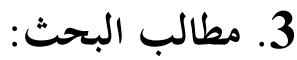

1.3 الفرض العلمي: الماهية والوظيفة: 1.1.3 ماهية الفرض العلمي:

الفرض Hypothesis كلمة مشتقة من اليونانية Hypothesis "تعني أساسي، مبدأ، إنشاء، طرح، نظري لم يتم البرهان عليه بعد، وبذلك يختلف عن النظرية العلمية التي 
تتسم بطابع اليقين" (صليبا،1971، 14). والفرض عند الفقهاء هو الوجوب، وهو ما يثبت بدليل قطعي أو ظني، أما عند الحكماء فهو التجويز العقلي، أي الحكم بجواز الشيء، وهناك نوعان من الفروض الأول انتزاعي، "أي إخراج ما هو موجود في الشيء بالقوة إلى الفعل، ولا يكون الواقع مخالفًا للمفروض، وي قول ديكارت أن أفرض ترتيبا بين الأمور التي لا يسبق بعضها بعضًا بالطبع إشارة إلى الفرض العقلي سواء كان مطابقًا للواقع أو مخالفًا له" (المرجع نفسه، 142).

وقد عُرفت كلمة فرض عند الإغريق بمعنى المبدأ العقلي الذي يسلم المرء بصحته دون أن يملك دليلاً عليه لشدة شيوعه، مثل قولنا المساويان لثالث متساويان، فهذه قضية يسلم بها الرياضي بداهة لشدة عمومها بين أهل الاختصاص. وقد أستعملها أفلاطون 1 بالمعنى نفسه، حيث إن كلمة فرض عنده كانت تدل على المبدأ العام الذي يستنبط منه جميع القوانين الفرعية. أما أرسطو² فقد عرف الفرض بأنه المنبع الأول لكل معرفة نكتسبها، ونقطة البدء في كل برهان نصل إليه. فيحين أن كلمة فرض في العصور الوسطى قد استعملت لتدل على القضايا العامة التي يستنبط منها الأحكام الجزئية التي تسمح بتنبؤ الظواهر في المستقبل. - اه

أما في العصور الحديثة فإن كلمة فرض استخدمت بمعنى الحدس أو التكهن، وهذا يعني أن الفروض في تلك الحقبة كانت عبارة عن تكهنات يضعها الباحثون لاكتشاف العلاقات بين الظواهر وأسباهما، "فهو حدس بالسبب في وجود الظاهرة، إذا صدق هذا

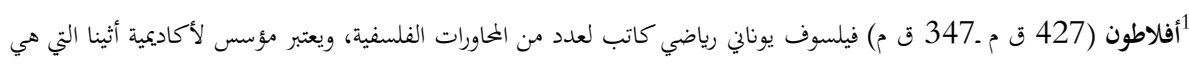

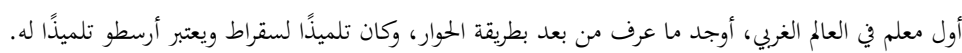

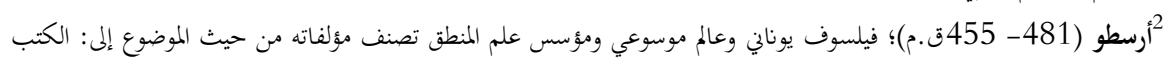

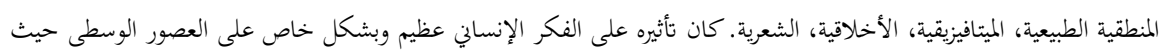

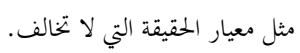


الحدس بعد اختباره أصبح قانونًا عامًا نرجع إليه في تفسير هذه الظاهرة عند تكرار حدوثها، أما إذا كذب الحدس فينغي البحث عن فرض آخر نتوقع صحته وصدقه في تفسير الظاهرة" (قربي، ب ت، 109)، وفي العلوم الرياضية تطلق كلمة فرض على الأوليات والمسلمات والتعريفات التي يستند إليها العالم في البرهان على إحدى القضايا، ثم يستنبط من هذه الفرضية بعض النتائج اللازمة عنها، أما في العلوم التجريبية فيمثلا لفرض العلمي تفسير مؤقت لحوادث الطبيعة، يتحول بعد الاختبار إلى تفسير فائي للظاهرة موضوع الدراسة، "فهو خطوة تمهيدية للقانون العلمي، يوضع في البداية على سبيل الظن والتخمين، فإن أيدته الوقائع كان قانونًا، وإذا لم تؤيده استبدل بغيره، وهكذا حتى نصل إلى فرضية تفسر الوقائع تفسيرًا صحيحًا" (صليبا، 1971، 143). فالفرض إذا جاء من الحبرة يعني أنه تم الاستفادة من الملاحظات والمعلومات السابقة، "أما إذا جاء نتيجة تخمين عقلي فإنه هنا بحاجة إلى الجانب التجريبي للتدليل عليه" (بجمع اللغة العربية، 1970،135). أما في المنطق فإن كلمة فرض استعملت بمعنى قضية توضع يتم التحقق من صدقها أو خطئها عن طريق الملاحظة أو التجربة. وقد قدم البُحاث عديد التعريفات للفرض العلمي، منها تعريف جون ستيوارت مل 1 الذي يرى أن الفرض هو "افتراض نتقدم به لاستنباط نتائج مطابقة للوقائع التي نعلم أها حقيقية" (عبد القادر، 1984، 78). وبالتالي فإن الفرض عنده مرتبط بالبحث عن علة الظاهرة، وقد قُدم تعريف للفرض تمثل في القول بأنه "عبارة عن جملة تقريرية بمعنى أها تقرر حدوث شيء ما يعبر بها الباحث عن تخمينه المبدئي للعلاقة التي يتوقع قيامها بين متغيرات الظاهرة التي يُعنى بدراستها"

1جون ستيوارت مل(1911- 1991) فيلسوف انجليزي اشتغل في المنطق ومناهج البحث العلمي اهتم بالاستقراء ووضع له طرق

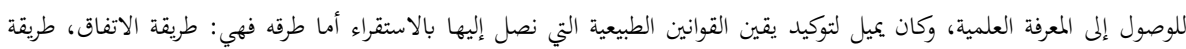
الاختلاف، طريقة التغير النسبي، طريقة الاتفاق والاختلاف معاً، طريقة البواقي. 
(الحصادي،1991،821). وهناك تعريف أخر للفرض يشير إلى ارتباطه بالتفسير تمثل في القول بأنه "اعتقاد في فهم الظواهر أو الاحداث في العالم وتفسيرها" (زيتون، 1991، 116). وهذا التعريف يؤكد على أن كل الفروض التي تُبنى منها النظريات والقوانين العلمية هي فروض تفسيرية. فالفرض أساس العلم، حيث إن العلم بمعناه الدقيق لا يكون إلا بفرض الفروض أولاً ثم محاولة التحقق منها ثانيا فهو عبارة عن "تعميمات من الخبرة، وهو أيضا استنتاج عقلي متدرج من مقدمات من مستوى رفيع أو مرتبة أعلى، وهذه كذلك اقتراحات أو تخمينات نشأت بحرية عن طريق العقل، وعندئذً يمكن خروج جمل مشتقة منها" (الحجوب، 2013، 35). والفروض منها ما هو عيني، ومنها ما هو مساعد؛ كرك "الفرض العيني هو ذلك الفرض الذي يوضع لتفسير ظاهرة بعينها، وليس له ما يثبته غير هذه الظاهرة، ولا يمكن اختباره مستقلا عن النسق ككل" (هبل، 1971، 43). في حين أن الفرض المساعد هو ذلك الفرض الذي تقوم على صدقه بينة مستقلة، وتثبته أمور أخرى غير التي وضع لتفسيرها. 2.1.3 وظيفة الفرض العلمي:

لقد أشاد الباحثون بقيمة الفروض في مجال البحث العلمي، باعتباره خطوة لابد منها في كل بحث علمي، وضرورة لا غنى عنها في كل استدلال تحريبي، وقد حددوا للفرض العلمي وظيفة مزدوجة في مجال العلوم التجريبية فهي "إما أن تسعى للكشف عن القوانين الثابتة وهي ما يطلق عليها فروض الدرجة الأولى، وإما أن تستخدم لتبيان مدى الصلة بين جمموعة من القوانين والتحقق والتثبت من صحتها وهي ما يطلق عليه فروض الدرجة الثانية" (الشنيطي، 1970، 139). ويجب الإشارة إلي أن وظيفة الفرض عند اتباع المنهج 
الاستقرائي 1 التقليدي تختلف عنه عند المنهج العلمي المعاصر أو ما يسمى بالمنهج الفرضي الاستنباطي حيث إن وظيفته عند اتباع المنهج الاستقرائي تكمن في كونه بجرد اقتراح وتفسير للملاحظات والتجارب، يصبح قانونًا إذا تطابق مع الملاحظات والتجارب، أما إذا لم يفسرها حكمنا عليه بالكذب وبحثنا عن فرض آخر، أما وظيفته عند اتباع المنهج العلمي المعاصر فهي متطورة "تتمثل في تقديم عدة تفسيرات تحيل الوقائع المتعثرة إلى وقائع مفسرة وأكثر نسقية" (عبد المعطي، 1985، 179). أي انها تكمن في تفسير القوانين التي سبق الوصول إليها بالطريقة الاستقرائية، لكنها مازالت تحتاج إلى الكثير من التفسير، فإذا ما قام الفرض بتفسير الوقائع المقبلة أصبح قانونًا، ومن ثم فإن جوهر الفرض العلمي هو أن يكون ممكن التحقق تجريبيًا، ومعيار صدقه يكمن في مطابقته للوقائع.

2.3

على الرغم من اتفاق جل العلماء والباحثين على القول بأن الفرض العلمي هو اقتراح مؤقت يضعه الباحث لتفسير الظاهرة التي يدرسها، إلا أفم يختلفون في تحديد المفهوم الذي ينطوي عليه مصطلح الفرض، حيث يذهب جون ستيوارت مل إلى أن الفرض

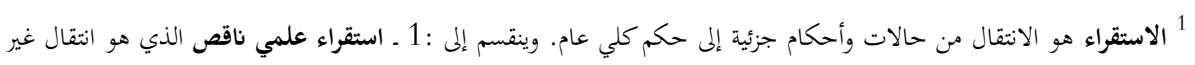

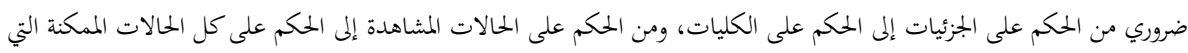

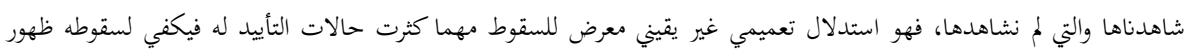

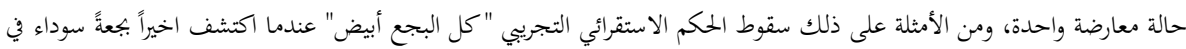

2ـ الاستقراء الرياضي الكامل فهو الانتقال من الحكم على بعض الحالات إلى الحكم على جميعها وهو استقراء يقيني بل كامل اليقين

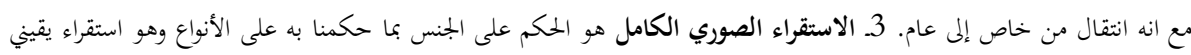

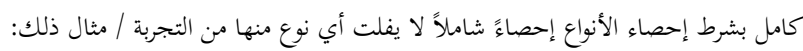

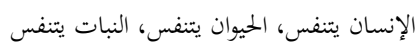
الإنسان والحيوان والنبات هي كل الكائنات الحية

كل الكائنات الحية تتنفس. 
ينطوي على تفسير علّي للطاهرة، ويشاركه فيذلك هيبن 1 الذي يرى أن الفرض عبارة عن افتراض يتعلق بالكشف عن علة الظاهرة. ولكن هذا التفسير العلّي للفرض لا يتفق مع علم ئميري

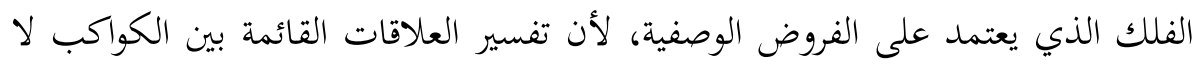

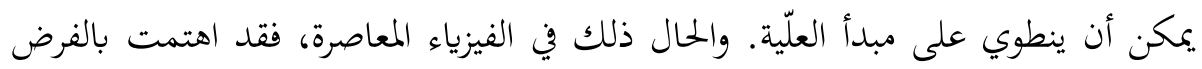

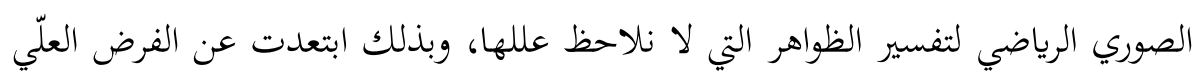

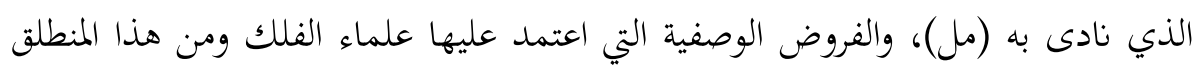
فإن الفروض العلمية ثلاثة أنواع: علّية، ووصفية، وصورية.

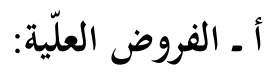

هي تلك الفروض التي يتم التحقق منها تجريبيا، وقد نادى بها جون ستيوارت مل الذي أكد على أن هناك علاقة ارتباط بين الفرض والعلّية، والسبب في هذا الارتباط هو

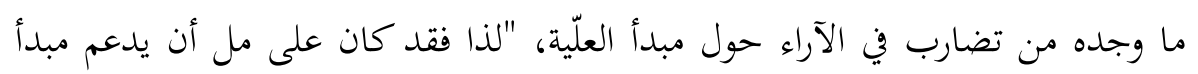
العلّية بما جعله ينسحب على ظواهر الطبيعة، ومن ثم نظر للقانون العلمي على أنه تفسير علّي" (عبدالقادر، 1984، 79). ومن ثم فإن مل ينظر إلى الفرض العلمي على أنى أنه ينصب على معرفة العلّة الحقيقية لحدوث الظاهرة، وقد اشترط مل على الفرض أن يقدم لنا

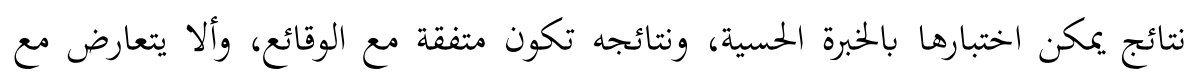
قوانين الطبيعة التي سلمنا بصدقها.

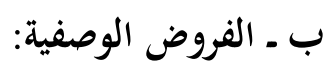

وهي المستخدمة في ميدان علم الفلك وتتمثل في الفروض التي لا تقوم على الاختبار التجريبي بل تعتمد بقدر كبير على خيال الباحث وفكرته عن الكون حيث يقوم الباحث "بإجراء عملية الاستباط الرياضي على الفروض التي لديه، ويتجه مرة أخرى لئي

1. جون هيبن (1861. 1933) ولد في بيويا إليون بالولايات المتحدة الامريكية، تميز بالرياضيات، شغل منصب رئيس جامعة برينستون

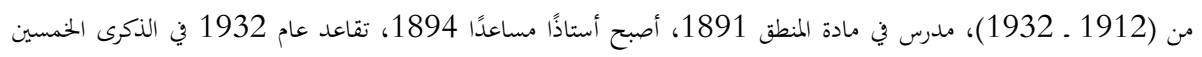

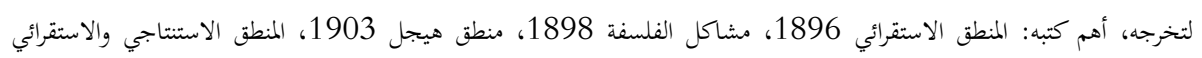
1905، فلسفة التنوير 1910. 
ببصره إلى السماء ليرى ما إذا كانت نتائج عملية الاستباط التي لديه تتفق مع ما

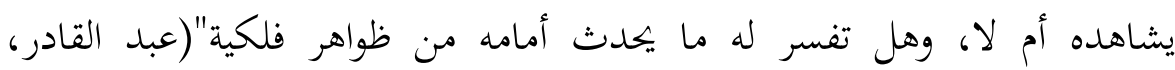
1984، 79). فإذا جاءت نتائجه متفقة مع ملاحظاته، كانت فروضه صحيحة أما إذا اختلفت معها فإن عليه في هذه الحالة أن يبحث عن فروض جديدة تفسر ما يلاحظه. ومن هذا المنطلق فإن الفرض الوصفي لا ينطوي على علاقات علّية، ولا يمكن التحقق منه بحريبياً من خلال إجراء التجارب المعملية، إنما عملية التحقق من صدقه تكمن

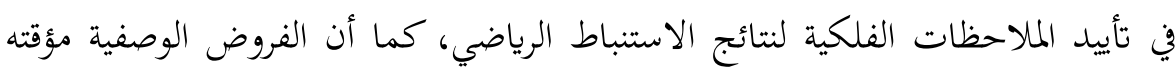
وقابلة للتطوير والتعديل وبذلك تختلف عن الفروض التجريبية.

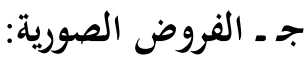

تتمثل في الفروض التي تتجاوز نطاق الملاحظة المباشرة؛ لأن التجربة المعملية عليها مستحيلة، فيكون الفرض بمثابة تصور رياضي للذهن، يقوم فيه الخيال العلمي

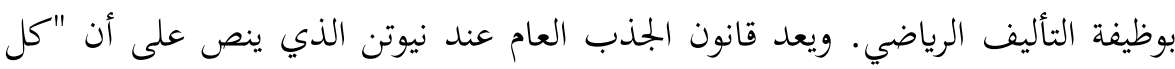

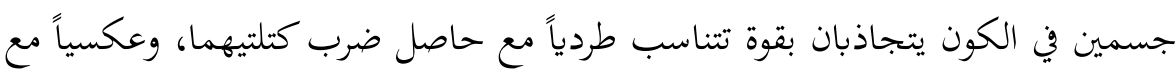
مربع المسافة بينهما" (المرجع نفسه، 90)، فرضاً صورياً يتجاوز نطاق الملاحظة المباشرة، إلا أنه قدم لنا تفسيراً عن الظواهر التي نلاحظها، وهو بهذا المعنى يقرر: "وجود كائنات

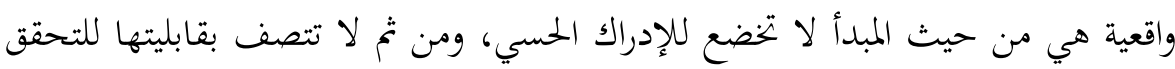

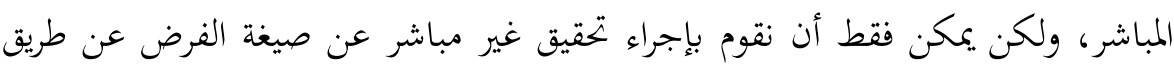
استنباط قضايا توضع موضع التحقق" (المرجع نفسه، 90). إضافة إلى ذلك فإن الفروض الصورية تتضمن تفسير قوانين النظريات التي سبق الوصول إليها، لتصبح هذه القوانين بمثابة نتائج مباشرة له.

\section{3}

من خلال تتبع اكتشافات العلماء وأعمالهم يتبين لنا أن هناك صلات وثيقة تربط بين الفرض والخيال والحدس، فكل الابتكارات التي تنعم بها البشرية الآن جاءت وليدة أما 
الخيال أو الحدس "فمن بين الحقائق الكيميائية استطاع خيال دالتون البناء أن يشيد النظرية الذرية، أما فاراداي ف2قد اعتمد على الخيال في جميع تجاربه، وترجع قدرته وخصوبته كمكتشف إلي القوة الدافعة للخيال" (نقلا عن: بيفردج، 101،1881). ويختلف الخيال العلمي عن الخيال الميتافيزيقي، وذلك أن الخيال العلمي وليد ملاحظة الواقع بما فيه من ظواهر يراد تفسيرها، فهو يبدأ من الظواهر ويرتد إليها، محا يمكن التحقق من صدقة عن طريق التجربة، في حين أن الخيال الميتافيزيقي يقوم على الفروض الميتافيزيقية، كما أن "وظيفة الخيال العلمي ليست مقصورة على العلوم الطبيعية وحدها في افتراض الفروض بل تدخل أيضاً في مختلف العلوم، خاصة العلوم الرياضية" (إسلام، 1977، 73). وبالتالي فإن الاعتماد على الخيال يؤثر في نجاح الفروض العلمية. وأهمية الحدس في الفرض لا تقل عن أهمية الحنيال، حيث يؤكد كارل بوبر $3{ }^{3}$ على أن كل كشف علمي ينطوي بالضرورة على عنصر لا عقلي أو حدس كشفي، أي إدراك موقف ما فجأة، ويتمثل في الأفكار التي توصف بأها وليدة الإلمام فعادة ما ترد هذه

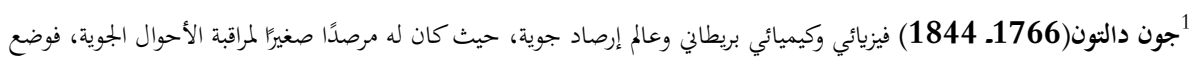

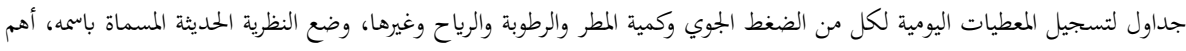

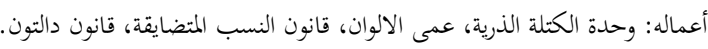

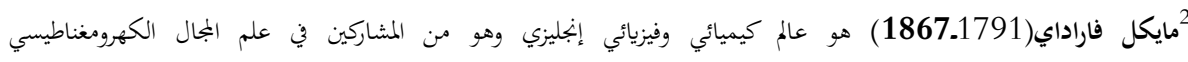

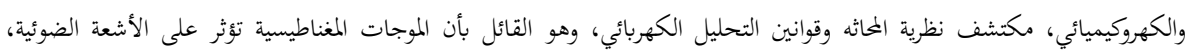

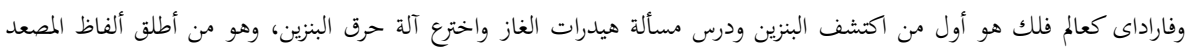
والمهبط والقطب والايون. 3 كارل بوبر (1902- 1994) فيلسوف نمساوي وعالم منطق واجتماع معاصر، له تطورات علمية ومعرفية وسياسية كبرى منها:

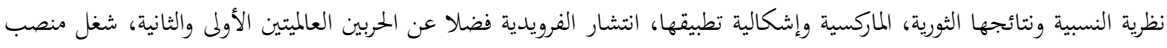

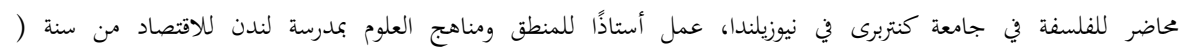

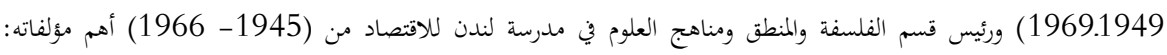

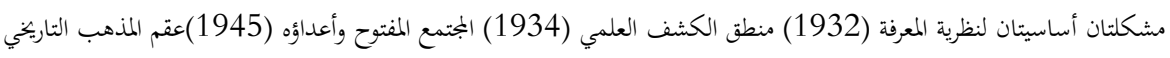

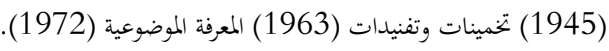


الأفكار للعالم في ومضة وقد عبر كلود برنار 1 عن مثل هذه الأفكار الحدسية بقوله: "قد يجدث أن فكرة ما أو ملاحظة ما تظل طويلاً أمام عين أحد العلماء دون أن توحي إليه شيئا وإذ بشعاع من نور يهبط عليه فجأة فيضي له السبيل ويستطيع الذهن حينئ أن يؤول هذه الواقعة نفسها تأويلاً جديداً مختلفاً كل الاختلاف عما سبق من تفسيرات، ويجد لها علاقات جديدة كل الجدة وتبدو هذه الفكرة الجديدة حيئذً بسرعة البرق كأها وحي مفاجئ" (نقلاً عن: موي، 1962، 405). وبناءً عليه قد شبه برنار الحدس بالنور الذي يهبط فجأة فيذهن العالم فيزوده بفكرة جديدة يستطيع من خلالما تفسير كل ما كان يصعب عليه وهذه الفكرة الحدسية تأتي للعالم في ومضة بسرعة البرق الخاطف. ومما تقدم يتبين لنا أن للحدس دورًا فعالَ في المنهج العلمي، فهو يمنحنا عددًا كبيرًا من الفروض الممكنة للطبيعة، الأمر الذي لئي يؤدى إلى التنوع في الملاحظات، التي بدورها لما دور في اختبار الفرض.

\section{( 4.3 شروط الفروض العلمية:}

إن عملية اقتراح الفروض هي مسألة ضرورية بحتة، فهي لا تخضع لأي قواعد عامة، ذلك لأن الناس يختلفون في قدراتم واستعداداهم لصياغة الفروض، فهي تعتمد على تصور الفرد لها، والعلوم الأخرى المتصلة بها. ومن ثم فإن أي اقتراح ليس بالضرورة أن يكون افتراضًا بالمعنى العلمي والمنطقي لهذا المصطلح، كما أننا لا نستطيع أن نضع قاعدة محددة لعدد الشروط التي تقيم أساس حقيقة فرض معين، إلا مبدأ توافقه مع الحقيقة والواقع، وانطلاقاً من مبدأ أن الفرض العلمي عنصر أساسي في مجال البحث عن ماهية الظاهرة وعلاقاتا، وكشف القوانين التي تسير بمقتضاها، فإنه يجب أن نحدد الشروط التي يجب

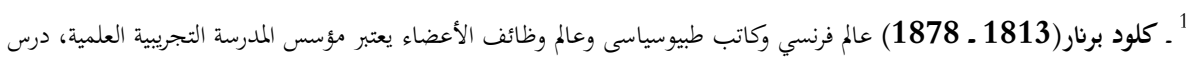

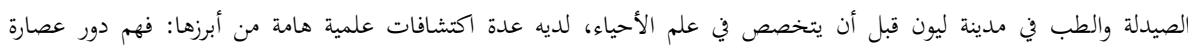

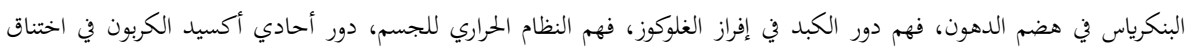

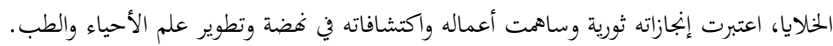


توفرها في الفرض لكي يصبح فرضاً علمياً صحيحاً، وتنقسم هذه الشروط إلى شرط مادي وشروط منطقية.

يتمثل الشرط المادي في القول بضرورة أن "ينبثق الفرض العلمي من واقع الملاحظة،

قبل أن يعتنق أي فكرة حتى لا يصل إلى فروض مضللة، قد تعوق عملية البحث وتصل به إلى نتائج مضللة" (بيفردج، 1801، 123). فكم من فروض خيالية قطعت صلتها بالواقع التجريبي فضللت الباحثين، مثال على ذلك ما حدث في القرن التاسع عشر، فقد افترض أحد الأطباء فرضاً من هذا النمط الخيالي التأملي المنقطع عن الواقع التجريبي مفاده: "أن ثمة سبباً يفسر معظم الأمراض المزمنة، إذ تنشأ نتيجة احتقان شديد يندفع في أثره الدم نحو العضو المريض فتضطرب وظيفته وتنحل أنسجته" (الشنيطي، 1970، 142)، وقد ترتب على هذا الخطأ خطأ آخر، "فأستنتج أن احتقان القناة الهضمية أخطر أنواع الاحتقان جميعا وإليه تعزى كل الأمراض المستعصية" (المرجع نفسه، 142). ونظراً لعدم التريث في الملاحظة والتجربة من قبل هذا الطبيب كان لهذا الفرض أخطار عديدة في علم وظائف

الأعضاء.

في حين أن الشروط المنطقية تتمثل في الآتي:

- يجب أن يكون الفرض العلمي غير متناقض مع ذاته وأن لا يناقض المفاهيم الموجودة فيه، فيجب على الباحث قبل أن يشرع في تحقيق فروضه بالتجربة الفعلية الحاسمة، أن يعمد إلى التحقق من صحته بالنظرة العقلية الثاقبة، بحيث لا يكون منافياً لنتائج أثنتها التجارب السابقة، وأن يغربل الفرض ويبتعد به عن كل شك، وألا يقوم بتصديق الآراء 
والأخذ بها، وإنما التحفظ عليها والتحقق منها. وذلك كما فعل جاليليو 1 عندما قام بإجراء تجاربه لتحديد القانون الطبيعي الذي تخضع له الأجسام في سقوطها حيث صاغ في البداية الفرض التالي "من المعقول أن تتناسب سرعة الجسم الساقط من مسافة قدمين ضعف سرعته وهو يسقط من مسافة قدم واحد" (المرجع نفسه، 142)، وبعد أن قام بتحليل الفرض تحليلاً رياضياً تبين له أنه ينطوي على التناقض، فعمل على استبعاده واستبدل به بفرض أخر تثثل في القول: "أن زيادة سرعة الجسم الساقط تتناسب تناسباً مطرداً مع ما يستغرقه من زمن في السقوط" (المرجع نفسه، 142). وبعد ما قام بإجراء تجاربه على هذا الفرض وفحصه رياضياً تبين له صحته فصاغه وأصبح قانوناً عامًا. كما يجب على الباحث ألا ينساق في بجاهل الغموض ويتعجل في الأخذ بالمظهريات والسطحيات، "فكثيراً ما انتشرت الفروض التأملية في العصور الوسطى المسيحية، وكانت مضللة ووهمية؛ لأهما بعيدة عن الواقع التجريبي مثل هذه الفروض أن هناك قوة للاحتراق كامنة في الأشياء الطبيعية" (المرجع نفسه، 143). - أن يتسم الفرض بجرأة التنبؤ والمواجهة المسبقة مع الواقع، وهذا النوع من الجرأة هو ما يميز الفرض العلمي، وأن يكون قابالً للاختبار، سواء بطريقة مباشرة أو غير مباشرة، وذلك كما حدث مع جاليليو عندما لم يستطع أن يبرهن بطريق مباشر على الفرض الذي فرضه والمتعلق بسقوط الاجسام "فاضطر إلى أن يستنتج قضايا أخرى ضرورية استطاع أن يبرهن عليها فيسر له ذلك البرهنة على الفرض الأصلي" . (الحجوب، 2013،40).

1جاليلو جاليلي (1221- 1215) رياضي وفلكي وفيزيائي وفيلسوف إيطالي دافع عن نظام كوبرنيكوس ضد متنقديه. بعد أن طور

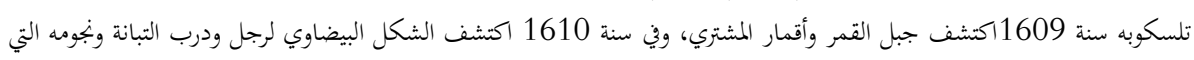

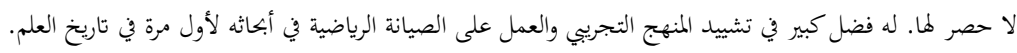


-ـ. يجب على الفرض أن يتحلى بالبساطة، وتعد البساطة من الأهمية بمكان بالنسبة لمفاهيم وقوانين ونظريات العلم الطبيعي، ويقصد بها احتواء الفرض في أقل عدد من المفاهيم، وموضوع البساطة نظراً لأهميته فلسفياً؛ اهتم به العديد من الباحثين من بينهم بوانكارئه

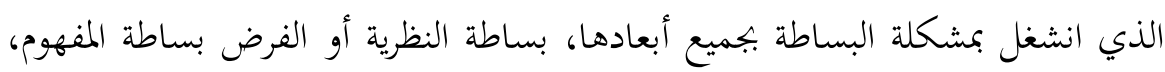
بل وحتى بساطة الوقائع إذ يقول: "على العالم أن ينتقي لموضوع دراسته أبسط الوقائع

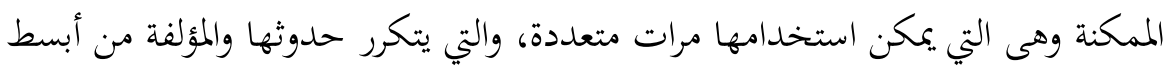

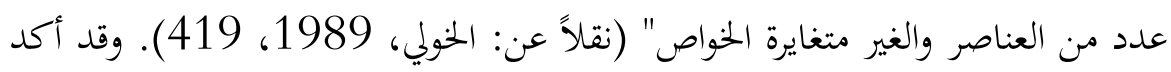
بوانكاريه على أن مبدأ الاختيار بين النظريات هو اختيار أبسط الاصطلاحات الممكنة حيث ميز بين الواقع المعقد من جهة، وبين القوانين العلمية البسيطة التي تفرضها عقولنا عليه من جهة أخرى، "فليست الطبيعة هي البسيطة، بل قوانيننا التي نفرضها عليها هي البسيطة؛ لأن القوانين هي التي تفرض ما تريده على عالم يكاد يكون مصطنعاً" (المرجع

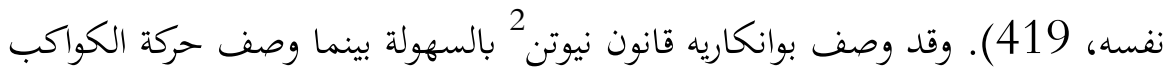

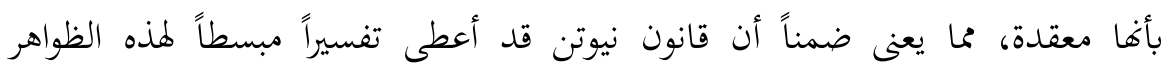
الطبيعية.

\section{3}

إن مرحلة اختبار الفرض من الأهمية بمكان في بجال البحث العلمي، يضع الباحث عند بحثه فروضًا مختلفة يتم اقتراحها على أها إجابات ممكنة، وبعد أن يقوم الباحث باقتراح

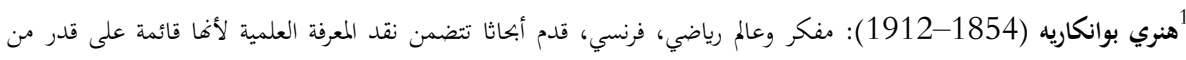

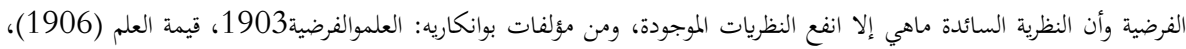

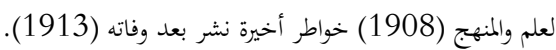
2اسحاق نيوتن (1642- 1727) فيزيائي ورياضي وصاحب فلسفة علمية إنجليزي، من مؤلفاته المبادئ الرياضية للفلسفة الطبيعية

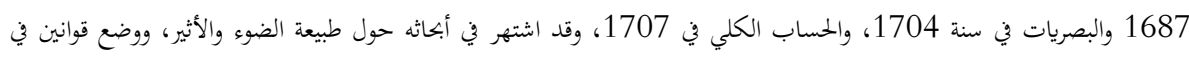

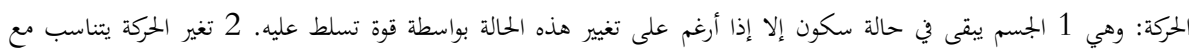
مقدار القوة المسلطة على الجسم. 3 ــ لكل فعل رد فعل مضاد له ومساو له. له. 
الفرض تأتي عملية اختباره، وذلك يكون بطريقتين: الأولى استقرائية، والثانية منطقية، وذلك على النحو التالي: (n)

1.5.3 1.3

يعتبر جون ستيوارت مل ممثلا للابحاه الاستقرائي، حيث قدم خمس طرق للتحقق من صدق الفروض العلمية، وهذه الطرق كما يرى مل هي وسيلة مشروعة للتأكد من صحة الفروض، فضلاً على أفها تنقل الفرض من وضعه كتفسير مؤقت إلى مرحلة كونه قانوناً، ومن الملاحظ أن فرنسيس بيكون ${ }^{1}$ قد سبق مل في الإشارة إلى هذه الطرق لكنه لم يقمها على أسس علمية راسخة فقد أغفل الدور الذي تؤديه الفروض في بجال البحث العلمي. ويمكن توضيح هذه الطرق في الآتي:

\section{1}

ومفادها أنه "إذا اتفقت حالتان أو أكثر للظاهرة المراد بحثها في عامل واحد كان هذا العامل الذي يثبت جميع الحالات هو علة الظاهرة أو معلوها" (الشنيطي، 1970، 145). فهذه الطريقة تمتم بالكشف عن علة الارتباطات العلية، فالعلاقة فيما بين العلة والمعلول هي علاقة متلازمة، فإذا وقعت أحدهما تتبعها الأخرى بالضرورة، وتطبيق هذه الطريقة يتطلب جمع أكبر عدد ممكن من الحالات وتنوعها، وعن طريق تنوع الحالات

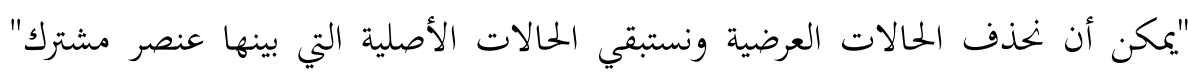
(عبد القادر، 1984، 105). وقد زودنا مل بمثال لطريقة الاتفاق تتمثل فيأن التركيب

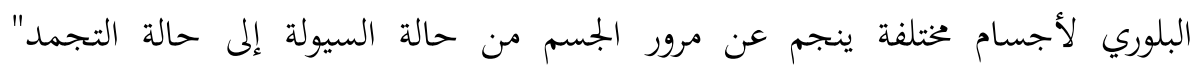
(الشنيطي، 1970، 146).

1فرنسيس بيكون (1561 - 1626) فيلسوف وكاتب وقاضي وسياسي ومحامي ومنجم إنجليزي، معروف بقيادته للثورة العلمية عن

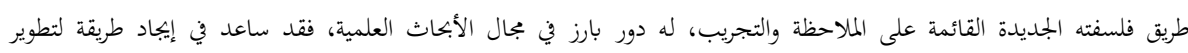

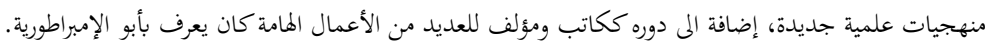


The Method of difference 2

وملخصها أنه "إذا كان هناك عاملان في ظاهرة معينة يتلازمان في الوقوع فإذا

حدث أن غاب العامل الأول ولاحظنا غياب العامل الثاني المالازم له، لاستخلصنا من هذا أن الأول علة للثاني" (المرجع نفسه، 146). وهذه الطريقة تقرر وجود اختلاف بين الحالتين فاذا كانت هناك حالتان متشابكتان في جميع الظروف باستثناء جانب واحد اختلفت فيه الحالتان، فإن هذا الجانب هو علة أو سبب الظاهرة فطريقة الاختلاف تقوم على أساس المقارنة بين ظاهرتين لندرك نقاط الاختلاف فيما بينهما. ومن الامثلة على هذه الطريقة العلاقة فيما بين الأكسجين والتنفس، فغياب الأول يؤدي إلى الاختناق وكذلك غياب المواء يفضي إلى انعدام الصوت" (المرجع نفسه، 146). 3 ـ طريقة الجمع بين الاتفاق والاختلاوف:

\section{The joint Method of agreement and difference}

مفاد هذه الطريقة يتمثل في أنه: "إذا كانت الحالتان التي توجد فيها الظاهرة التي ندرسها تشترك في ظرف واحد في حين أن الحالتين التي لا توجد فيها الظاهرة لا تشترك إلاّ في عدم وجود هذا الظرف، فإن الظرف الوحيد الذي تختلف فيه المجموعتان من الحالات إحداهما عن الأخرى هو معلول الظاهرة"(عبد المعطي،1985،1865).وخلاصة هذه الطريقة تكمن في القول بأنه إذا حضرت العلة حضر المعلول وإذا غابت العلة غاب المعلول، فالعلة تدور مع معلولها وجوداً وعدماً، فالفرض يكون صحيحاً بناءً على الاتفاق والاختلاف فيما بين الحالات.

\section{The Method of concomitant variation 4} وتتمثل في أنه "مهما كانت الظاهرة متغيرة بصورة ما، كلما تغيرت ظاهرة أخرى بنفس الصورة التي تغيرت بها الأولى، فهي إما علة أو سبباً لهذه الظاهرة، أو أها ترتبط بها 
ارتباطاً علّياً" (عبد القادر، 1984، 109). وتسمى بطريقة التلازم في التغير بمعنى أنه أي تغير يحدث للعلة فإنه يتبعه بالضرورة تغير في المعلول، وتعد هذه الطريقة من أهم طرق على الاطلاق وأهميتها ترجع إلى طابعها العلمي؛ ذلك لأها "لا تستلزم إيجاد العلاقة بين

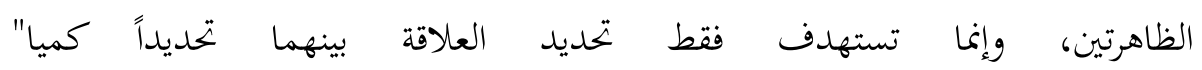
(الشنيطي،1970،147). وهذه الطريقة تعطينا نتائج دقيقة، خاصةً إذا كنا بإيزاء تغير كمي يمكن قياسه، فضلاً على أن العلوم التجريبية المتقدمة تعبر عن العلاقات بين الظواهر في صيغ كمية، نعبر عن قوانينها بصيغ رياضية أو رسوم بيانية. ومن الأمثلة على هذه

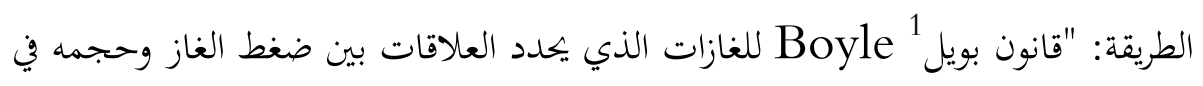
صيغ دقيقة تقرر أن الضغط والحجم يتناسبان عكسياً في درجة الحرارة الثابتة" (عبد القادر، (110، 1984

5 ـ طريقة البواقي:The Method of Residues

وتقرر أنه "إذا اسقطنا من أي ظاهرة ذلك الجزء الذي سبق معرفته بالاستقراء على أنه السبب في إنتاج مقدمات معينة، فإن ما يستبقي من الظاهرة يعد سبباً للمقدمات التي لدينا" (المرجع نفسه، 108)، ومعنى هذا "أننا حينما نعلم جميع علل الظاهرة عدا علة واحدة فإن المتبقي من الظاهرة (المعلول) يكون نتاج المتبقي من الظاهرة الأولى (كعلّة)" (عبدالمعطي، 1985، 186). طريقة البواقي فيما يرى مل هي تطوير لطريقة الاختلاف، كما أها من أهم الطرق المؤدية إلى الكشف العلمي. وقد أورد مل المثال التالي على هذه

1وربر وليام بويل (1627-1690) انجلو ايرلندي فيلسوف طبيعي كيميائي فيزيائي ومختع، يعد من أبرز الذين عملوا في بجال الغازات

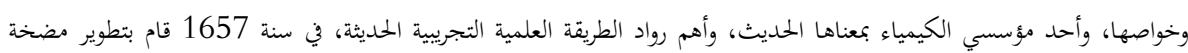

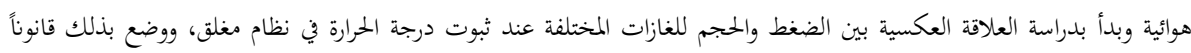

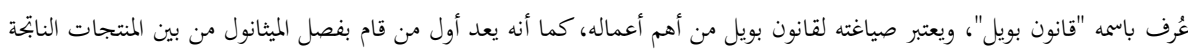

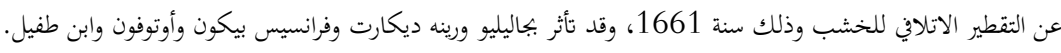


الطريقة: "إذا علقنا إبرة ممغنطة بخيط من حرير ثم حركناها فوق وعاء من نحاس لشاهدنا أن رجوعها إلى السكون أسرع، وليس أمامنا إلاّ عاملان يمكن اعتبارهما علة لهذه الظاهرة، وهما مقاومة الهواء ومقاومة الخيط، فإذا أسقطنا تأثير هذين العاملين لم يعد لدينا إلاّ سبب واحد وهو وعاء النحاس فهو المعوق لحركة الإبرة" (الشنيطي، 1970، 147). ويلاحظ على طريقة البواقي أها وسيلة من وسائل اختبار الفروض التي يضعها العالم، لكنها ليست وسيلة من وسائل البرهان، كما أها "تقوم على الحذف، وعلى مبدأ أن علة شيء ما لا يمكن أن تكون علة كل شيء" (عبد المعطي، 1985، 190). 2.5.3

يتبع العلماء إحدى القواعد المنطقية الآتية في اختبار فروضهم العلمية:

1 ـ القاعدة المنطقية الأولى التي يتبعها العلماء في اختبار فروضهم العلمية تصاغ في صورة قياس شرطي متصل في صورة نفي المقدم، حيث ترى بأنه "إذا أظهرت التجارب أن مضمون الاختبار كاذب فإن الفرض بناء على ذلك سيكون مرفوضًا، والاستدلال المؤدي إلى رفض الفرض يمكن توضيحه على النحو"(زيدان،45،

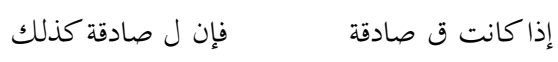
لكن ل كما يظهر بالدليل كاذبة صادة صادة

إذن ق كاذبة .

فالفرض يكون كاذبًا، إذا وجدت حالة سلبية واحدة تتعارض معه، أي إذا كانت نتيجته غير مطابقة للواقع. 2 ـ أما القاعدة المنطقية الثانية فهي على العكس من الأولى حيث ترى بأنه "إذا أيدت التجربة صدق مضمون الاختبار، فإن النتيجة المؤيدة من قبل التجربة لا تثبت بشكل هائي أن الفرض صادق، وسيأخذ الاستدلال صورة الشكل الآتي" (همب، 1976 ،12): 


$$
\text { إذا كانت ق صادقة }
$$

\section{إذن ق صادقة}

وهذه الصورة من الاستدلال فاسدة منطقياً، أي أن "النتيجة لا تلزم عن المقدمات بالضرورة، أو أن النتيجة قد تكذب حتى لو صدقت المقدمات، وتسمى هذه الصياغة

$$
\text { (اغلوطة إثبات التالي)" (زيدان، 1989، 1996). }
$$

3 ـ اختبار الفرض قد يقوم على استنتاج نتيجة تتسق مع الظاهرة المراد دراستها، بحيث "تسمح هذه النتيجة بملاحظات أو بتحارب محسوسة، ففي هذه الحالة تستخدم صيغة القياس الشرطي المتصل في صور إثبات التالي" (المرجع نفسه، 44). وإذا ما صيغت في صور استدلال علمي نقول: "إذا شوهدت حالات جزئية من نوع معين ل صدق الفرض، لكن الحالات الجزئية ل شوهدت، إذا ق صادقة. وهو ما يعبر عنه بالصورة الرمزية الآتية" (المرجع نفسه، 44) (14)

$$
\text { إذا كانت ق صادقة }
$$

\section{إذاً ق صادقة}

خن هنا بصدد استدلال استقرائي ننتقل فيه من مقدمة جزئية إلى نتيجة لما طابع القانون العام، وبالرغم من أن هذا الاستدلال صحيح استنباطياً، لكن صدق المقدمات لا يتضمن صدق النتيجة. 4. (4) النتائج: 1 ـ الفرض العلمي ليس غاية في ذاته، بل وسيلة لتحقيق غاية، فهو مرحلة مؤقته يتحول إلى قانون أو نظرية عندما تؤيد نتائجه التحقق التجريبي، فيصبح تفسير صحيحًا للظاهرة 
موضع البحث، فيحتفظ الفرض بقيمته عندما تتحقق نتائجه، ويفقدها فيحال لم تتحقق، ويتم ذلك إما عن طريق الاختبار التجريبي الذي يؤيد الفرض أو يفنده، وإما عن طريق تأييد أو تفنيد الوقائع له.

2 تختلف وظيفة الفروض باختلاف المنهج المتبع في دراستها، فاتباع المنهج الاستقرائي ينظرون إلى الفرض العلمي على أنه ججرد اقتراح للمالحظات والتجارب، يصبح قانونًا إذا تطابق معها، أما إذا فشل في تفسيرها حُكم عليه بالكذب وبُحُث عن فرض آخر، أما أتباع المنهج الاستباطي فإن وظيفة الفرض عندهم تكمن في تقديم عدة تفسيرات تحيل الوقائع المتعثرة إلى وقائع مُفسرة، فجوهر الفرض هو أن يكون محكن التحقق بتريبيًا، ومعيار صدقه يتوقف على مطابقته للوقائع. 3 ـ يعد الفرض خطوة هامة في كل بحث علمي، بل يعتبر ضرورة لا غنى عنها في كل استدلال بتريبي، لأنه يقدم وظيفة مزدوجة، فهو من جهة يسعى للكشف عن القوانين الثابتة ومن جهة أخرى يستخدم لبيان مدى الصلة بين مجموعة من القوانين والتحقق منها

$$
\text { والتبتت من صحتها. }
$$

4 ـ توجد نوعين من الفروض التي يبرهن عليها في العلوم التجريبية: فرض علّي يتعلق بالكشف عن علة الظاهرة، توحى لنا به الملاحظات والتجارب، يتحول بالتحقق التجريبي إلى قانون. وفرض صوري يتجاوز نطاق الملاحظة المباشرة لأن التجربة المعملية عليه مستحيلة، يستنتج من القوانين والنظريات السابقة، يتحول بالتأييد التجريبي لما يستنبط منه من نتائج تقبل التحقق التجريبي إلى نظرية برهانية تكون بمثابة تأكيد وتدعيم للقوانين التي صدرت عنها. وهناك نوع ثالث من الفروض يبرهن عليها في علم الفلك، ويتمثل في الفرض الوصفي، وهو لا يقوم على الاختبار التجريبي، بل يعتمد علي خيال الباحث 
وفكرته عن الكون، وعملية التحقق من صدقه يكمن في تأييد الملاحظات الفلكية لنتائج الاستنباط الرياضي، وهو فرض مؤقت قابل للتطوير والتعديل. 5 ـ يشترط في الفرض العلمي أن يكون مستوحى من الملاحظات والتجارب، وأن يكون قابلاً للبرهان التجريبي، وأن يكون شاملاً لأكبر قدر من الوقائع التي من الممكن أن تستنبط منه، وأن يكون قادرًا على تفسير الوقائع والظواهر التي وضع لأجلها والتنبؤ بها، وألا يكون متعارضًا مع أي قانون سبق قبوله، وأن يكون مُصاغًا صياغة دقيقة موجزة لا تحتوي على أيتاقض، كما يجب على الباحث أن يضع عددًا محدودًا من الفروض أو الاحتمالات الممكنة؛ وذلك ليتمكن من اختبارها الواحد تلو الآخر، ليصل إلى الفرض الذي تؤيد التجربة نتائجه.

6 ـ يعد الفرض من أكثر صور التعبير عن الظاهرة إنتاجًا وإبداعًا؛ ذلك لأنه ينطوي على خيال علمي وتخمين وحدس عقلي، يجعلنا ندرك كل ما نكتشفه أو نبرهن عليه، ومن ثم فهناك علاقة وثيقة تربط فيما بين الفرض والخيال والحدس.

\section{المصادر والمراجع}

إسلام، عزمي (1977). مقدمة لفلسنة العلوم، مكتبة سعيد رأفت، القاهرة.

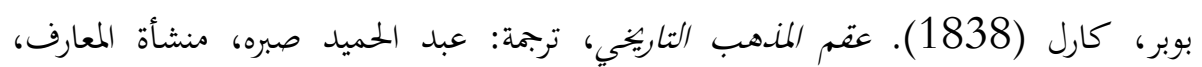

$$
\text { الإسكندرية. }
$$

بوبر، كارل (1880). منطق الكشف العلمي، ترجمة وتقديم: ماهر عبد القادر، دار النهضة العربية، بيروت.

بيفردج (1801). فن البحث العلمي، ترجمة: زكريا فهمي، مراجعة: أحمد مصطفي أحمد، دار النهضة العربية، القاهرة. 
الحصادي، نجيب (1991). غه المنهج، ط1، الدار الجماهيرية للنشر والتوزيع والإعلان،

$$
\text { مصراتة - ليبيا. }
$$

الخولي، يمنى طريف (1989). فلسنة كارل بوبر: منهج العلم، منطق العلم، الهيئة المصرية العامة للكتاب.

$$
\text { زيتون، عايش (1991).طبيعة العلم وبنيته، ط2، دار عمار، عمان - الاردن. }
$$

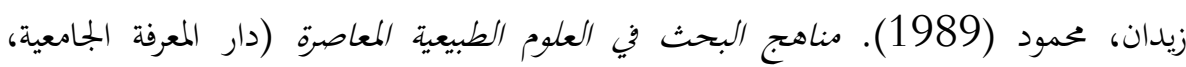

$$
\text { الإسكندرية). }
$$

السرياقوسي، محمد (1986). التعريف بمناهج العلوم، دار الثقافة للطباعة والنشر، القاهرة. سكران، فايز يوسف محمد (1993) الفروض العلمية مع مناقشة موقف المعارضين لها من المعاصرين. (رسالته دكتوراه منشورة). جامعة الإسكندرية، كلية الآداب، قسم الفلسفة. الشنيطي، محمد فتحي (1970). اسس المنطق والمنهج العلمي، دار النهضة العبية للطباعة والنشر ، بيروت.

$$
\text { صليبا، جميل (1971). المعجم الفلسفي ج1، ، دار الكتاب اللبناني، بيروت. }
$$

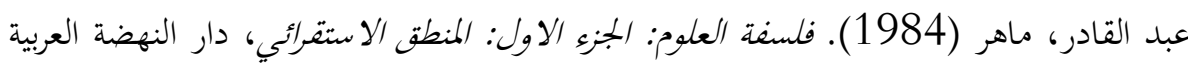

$$
\text { للطباعة والنشر، بيروت ـ لبنان. }
$$

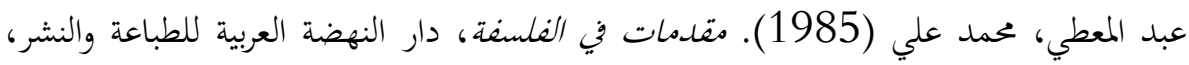
بيروت، لبنان.

قرني، عزت (بدون تاريخ). مدخل إلى الفلسغة، دار النهضة، القاهرة.

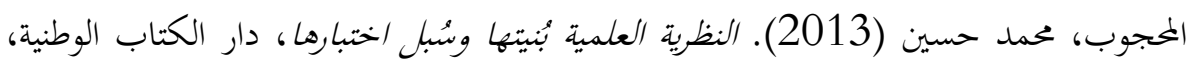

$$
\text { بنغازي- ليبيا. }
$$

مجمع اللغة العربية (1970). المعجم الفلسفي، الهيئة العامة للطباعة، القاهرة.

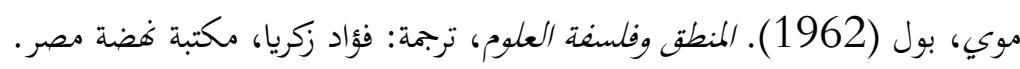

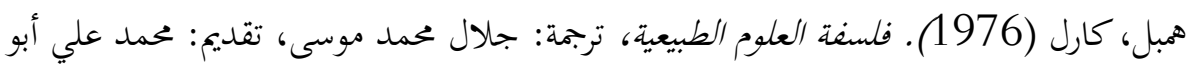
ريان، ط1، دار الكتاب المصرية، القاهرة. 